Poster presentation

\title{
Treatment of calcinosis with biphosphonates in juvenile dermatomyositis Y Bilginer ${ }^{1}$, R Topaloglu*1 and N Gonc ${ }^{2}$
}

Address: ${ }^{1}$ Hacettepe University School of Medicine, Pediatric Nephrology and Rheumatology, Ankara, Turkey and ${ }^{2}$ Hacettepe University School of Medicine, Pediatric Endocrinology, Ankara, Turkey

* Corresponding author

from I5th Paediatric Rheumatology European Society (PreS) Congress

London, UK. 14-17 September 2008

Published: 15 September 2008

Pediatric Rheumatology 2008, 6(Suppl I):P220 doi:I0.II86/I546-0096-6-SI-P220

This abstract is available from: http://www.ped-rheum.com/content/6/SI/P220

(C) 2008 Bilginer et al; licensee BioMed Central Ltd.

Juvenile dermatomyositis (JDM) is a multisystem disease that is characterized by nonsuppurative inflammation of striated muscle and skin. Dystrophic calcification occurs in up to $40 \%$ of children We present our treatment approach in four JDM patients with calcinosis. Four female patients (median age 8.5 years, range 6-14) had been diagnosed as JDM in our center. Two of them presented with severe disease and calsifications in the the other two, despite successful treatment of myopathy with steroids, methotrexate and cycylosporin, calcinosis had developed within 10 months (ranging 4-16 months) of initial diagnosis. Two of the patients who had generalized calcinosis and severe osteoporosis were given iv pamidronate and the other two were treated with oral alendronate in addition to oral diltiazem, calcium and vitamin D supplementation. After 7 months of treatment (ranging 5-14 months) clinical and radiological examination revealed dramatic regression of the calcinosis. Bone mass improved as determined by bone absorptiometry. Biphosphonates oral or iv according to the severity of the disease could be a useful therapy in patients with JDM and calcinosis in addition to aggressive therapy of inflammation. 